\title{
ОЦЕНКА ЭФФЕКТИВНОСТИ И РЕЗУЛЬТАТИВНОСТИ СИНЕРГИИ ПРИ СЛИЯНИЯХ И ПОГЛОЩЕНИЯХ
}

\author{
(c) 2019 Зимин Владислав Владимирович \\ аспирант \\ Финансовый университет при Правительстве Российской Федерации, Россия, Москва \\ E-mail: vladislav14@rambler.ru
}

В статье описываются методологические основы оценки синергетического эффекта при слияниях и поглощениях. Автор проанализировал существующие подходы оценки эффективности и результативности синергизма и выявил их недостатки. Важное значение при оценке эффективности играют затраты, которые понесет компания вследствие осуществления интеграции. Учет всех затрат в совокупности с рекомендуемыми подходами приведет к более точной оценке эффективности до совершения сделки и результативности после ее реализации.

Ключевые слова: синергетический эффект, синергия, оценка результативности, оценка эффективности, слияния и поглощения, методика оценки.

Целью любого бизнеса является рост, расширение и улучшение производительности труда в целях извлечения прибыли. Стратегии слияний и поглощений выполняют эту роль для организаций уже шестое десятилетие [5]. Слияния и поглощения являются неотъемлемой частью глобального стратегического и финансового бизнес-ландшафта, в котором участвуют не только приобретающая и целевая компании, но и другие заинтересованные стороны: бухгалтера, юристы, инвесторы [10].

Оценка синергетического эффекта является основой успешной реализации сделки по слиянию и поглощению. «Успех» заключается в положительной разнице между рыночной стоимостью объединенной компании и стоимостями двух корпораций до слияния и поглощения. В каждой сделке и покупатель, и продавец должны оценить стоимость компании с учетом синергетического эффекта и сделать вывод о благоприятных или неблагоприятных условиях сделки для их интересов.

Компании могут преследовать различные цели, принимая решения о слиянии и поглощении. Мотивы компаний могут быть классифицированы разными способами и имеют различный характер. Одной из классификаций [11] можно предложить разделение мотивов с точки зрения увеличения стоимости фирмы (и благосостояния акционеров, соответственно) и увеличения состояния менеджера, поскольку они могут получать вознаграждение не только в свя- зи с расширением компании, но и просто при реализации сделки, даже невыгодной акционерам. Например, многие исследователи выделяют личностный мотив менеджеров, нашедший отражение в «теории гордыни» [12], согласно которой решение о слиянии принимает менеджер индивидуально и считает, что его оценка верна, даже если объединение не принесет положительного синергетического эффекта.

Кроме того, основные мотивы могут быть разделены на операционные, финансовые и инвестиционные [3], то есть, исходя из вида синергии: операционной, финансовой и инвестиционной, соответственно [1]. Например, к операционной можно отнести экономию от масштаба или вертикальной интеграции, к финансовой налоговые мотивы или диверсификацию, к инвестиционной - приобретение новых активов за счет сделки, нежели через покупку.

Независимо от мотивации сторон в реализации сделки основная задача слияний и поглощений заключается в том, чтобы помочь предприятиям создать большую ценность компании, чем они создают сейчас сами по себе. Большинство эмпирических исследований по этому вопросу показали, что слияния и поглощения не были столь успешными, как ожидалось, и главным фактором, оказавшим негативное влияние, было неточное определение стоимости компании [7; 8]. Так, Brotherson, W. Todd \& Eades, Kenneth M. \& Harris, Robert S. \& Higgins, Robert С. исследовали 11 крупных инвестиционных банков путем 
интервьюирования в течение 11 лет, Bruner R.F. обобщил доказательств 130 исследований, из которых только 20\% были удачны.

Для оценки эффективности и результативности синергии существует много подходов. Многочисленные исследования проводятся с предположением, что слияния и поглощения похожи по своей природе, однако в действительности это не так [6; 9]. Оценка является сложным процессом, поскольку каждая компания индивидуальна - у каждой корпорации собственные цели, задачи и стратегии, основные направления и рынки функционирования. Также и сами сделки отличаются между собой в силу воздействия различных внешних и внутренних факторов.

Оценка синергии основывается на сравнении прогнозного значения (потенциального) синергизма до и фактического значения после совершения сделки по слиянию и поглощению. Таким образом, оценка основывается на результативности сделки, которая и подразумевает соотношение между фактическим и плановым результатами.

Основой для всеобъемлющей оценки выступает стоимость компании, определяемая в соответствии с Федеральным стандартом оценка № 8 «Оценка бизнеса» [2]. Модель оценки может использовать несколько методов в рамках трех фундаментальных подходов:

1. Доходный

Самым распространенным методом оценки в рамках данного подхода при оценке стоимости является комбинация метода дисконтированных денежных потоков и метода капитализации. Алгоритм оценки предполагает определение стоимости оценки компании-цели и компании-покупателя до реализации сделки и суммирование результатов, выявление факторов изменения расчетных значений, определение стоимости объединенной компании через дисконтирование и расчет синергетического эффекта через разницу между стоимостью компании после и до осуществления сделки. Данный подход не учитывает все затраты на реализацию сделки, что приводит к искажениям в стоимости.

\section{2. Затратный}

Использование данного подхода определяет синергетический эффект как увеличение стоимости имущества объединенной компании. Сложность использования данного подхода заключается в трудоемкости расчета и оценки нематериальных активов.

\section{3. Сравнительный}

Как правило, применяется для отбора кандидатов для слияния и поглощения и включает в себя метод рынка капитала и метод сделок. Алгоритм расчета основывается на анализе компаний-аналогов путем использования ценовых мультипликаторов. Основным недостатком данного подхода выступает отсутствие полностью одинаковых компаний-аналогов, вследствие чего компания может быть переоценена или недооценена.

Наиболее используемым подходом в научной литературе [4; 7] выделяется доходный подход, однако для оценки стоимости компании с учетом синергии наиболее подходящим считается затратный подход, а именно, метод чистых активов, так как доходный подход носит более вероятностный характер и сопряжен с трудностями: не подходит для компаний, у которых отсутствуют доходы длительный промежуток времени [4]. Затратный подход является более точным, так как основывается на имеющихся активах.

Наиболее используемым подходом в научной литературе [4; 7] выделяется доходный подход, поскольку сравнительный и затратный учитывают текущие или ретроспективные значения, соответственно. Метод дисконтированных денежных потоков в рамках доходного подхода определяет стоимость в соответствии с показателями, приведенными к будущим значениям, и рисками компании.

Хотя слияния и поглощения фактически являются инвестиционным решением, они требуют более тщательного анализа и учета различных факторов. Воздействие этих факторов, внутренних, например, прогнозные величины основных финансовых показателей, и внешних, например, процентная ставка, может оказать влияние на потенциальное значение синергетического эффекта.

При оценке эффективности важно правильно определить затраты для расчета потенциальной величины синергетического эффекта. Ожидаемые выгоды должны перевешивать затраты для успешной реализации сделки, поскольку главной целью функционирования корпорации является получения прибыли и улучшение благосостояния акционеров. В целом затраты можно разделить на два вида:

1. Расходы на поиск, оценку и переговоры, которые зависят от опыта компании в области 
слияния и поглощения. Сделки по слиянию и поглощению - сложный процесс, требующий много времени, поэтому, когда фирма уже имеет опыт работы с такими сделками, она может более эффективно управлять этим процессом.

2. Премия и затраты на интеграцию, которые зависят от информации, которую участник торгов имеет о компании-цели. Одним из рисков, связанных с приобретением, является переплата за компанию-цель. И когда покупающая сторона уже имеет информацию о стоимости компании-цели, она может лучше оценить потенциальный синергизм. Одним из методов, используемых для устранения информационного пробела, является участие компаниипокупателя в целевой компании с помощью минимального пакета акций. Таким образом, покупатель может собирать соответствующие данные о цели гораздо более экономичным способом. Облегчая информационный поток за счет наличия небольшой доли собственности в целевой компании, приобретатель может точно оценить истинную стоимость и потенциальные выгоды от слияния.

Если подходы оценки синергетического эффекта имеют в своей основе прогнозирование, то оценка результативности сделки предполагает использование ретроспективного анализа, то есть основывается на фактических данных после реализации сделки. При оценке результативности также выделяют несколько подходов:

1. Бухгалтерский подход предполагает сравнение финансовых показателей до и после реализации сделки.

2. Рыночной подход основан на изучении изменений показателей фондового рынка до и после интеграции, например, прибыль на акцию или норма дивидендного дохода.

3. Комбинированный подход изучает связь между изменениями финансовых показателей и показателей фондового рынка.

Для комплексного анализа наиболее предпочтительным является комбинированный метод. Использование элементов бухгалтерского подхода позволит определить влияние синергии на рост благосостояния акционеров, именно то, для каких целей сделка и реализовывалась. Элементы рыночного подхода оценивают показатели, связанные с доходностями акций, что также является немаловажным фактором успешности осуществления сделки.

Исходя из описанного выше, можно сделать вывод, что оценка синергетического эффекта основывается на оценке эффективности сделки слияния и поглощения путем прогнозирования, на основе которой принимается решение о дальнейшей интеграции и последующей оценке результативности по факту совершения сделки. При использовании рекомендуемых методов эффективность синергетического эффекта будет точной, поскольку учитываются все затраты реализации сделки, влияющие на стоимость компании, а результативность сделки слияния и поглощения должна быть положительной.

\section{Библиографический список}

1. Бабенко И.А., Бадюков В.Ф. Оценка экономического эффекта при слияниях и поглощениях компаний // Вестник ТОГУ, 2015. № 2 (37). С. 185.

2. Об утверждении федерального стандарта оценки «Оценка бизнеса (ФСО № 8): приказ Министерства экономического развития и торговли российской Федерации от 01.06.2015 № 326 [Электронный ресурс] // Оценщик.py. URL: http://www.ocenchik.ru/news/2168.html (дата обращения: 27.08.2019).

3. Фадейкина Н. Основы мотивации и синергетические эффекты сделок слияния и поглощения компаний // Риск: ресурсы, информация, снабжение, конкуренция, 2012. № 4. С. 509-519.

4. Шевченко И.В., Волков Ю.В. Проблемы оценки эффективности сделок слияний и поглощений в посткризисный период экономического развития России // Финансы и кредит, 2012. № 30 (414). С. 11-16.

5. Bellou V. Psychological contract assessment after a major organizational change: the case of mergers and acquisitions // Employee Relations, 2007, Volume 29. Issue 1.pp. 68-88

6. Bower JL. Not all M\&As are alike - and that matters // Harvard Business Review, 2001, Volume 79, Issue 3. pp. 92-101.

7. Brotherson, W. Todd \& Eades, Kenneth M. \& Harris, Robert S. \& Higgins, Robert C. Company Valuation in Mergers and Acquisitions: How Is Discounted Cash Flow Applied by Leading Practitioners? // Journal of Applied Finance, 2014, Volume 24, Issue 2. pp. 43-51.

8. Bruner RF. Does M\&A pay? A survey of evidence from the decision-maker // Journal of Applied Finance, 2002, Volume 12, Issue 1. pp. 48-68. 
9. Joash GO, Njangiru MJ. The effect of mergers and acquisitions on financial performance of banks (a survey of commercial banks in Kenya) // International Journal of Innovative Research \& Development, 2015, Volume 4, Issue 8. pp. 101-113.

10. Moeller S., Brady Ch. Intelligent M\&A: Navigating the Mergers and Acquisitions Minefield / Moeller S., Brady Ch. United Kingdom: John Wiley \& Sons, Inc., 2014. 328 p.

11. Motis J. Mergers and Acquisitions Motives / Motis J. Toulouse School of Economics - EHESS (GREMAQ) and University of Crete, 2007. 31 p.

12. Roll R. The Hubris Hypothesis of Corporate Takeovers // Journal of Business, 1986. № 2. 198 p. 